\title{
Social Insurance for Oral Healthcare: Analysis of Two Insurance Schemes in India
}

\author{
Umashankar Gangadharaiah Kadaluru, Rukmini Jinnagara Naryanappa²
}

\begin{abstract}
Objective: To assess the equity, access, and utilization of social health insurance schemes in India for oral healthcare services.

Methodology: A case study approach was used with both qualitative and quantitative information, which was collected from various sources like personal interviews of informed persons in the scheme, annual reports of the scheme, and through the Right to Information Act 2003.

Results: Employees' State Insurance (ESI) Scheme and Central Government Health Scheme (CGHS) are the large and oldest social insurance schemes implemented in India, covering approximately $12 \%$ of the population who are working in organized sectors. In terms of dental health, both the schemes provide a range of services through their centers without any capping or sealing for dental services. It also outsources the services through empaneled healthcare organizations with reimbursement mechanisms for 58 approved procedures with fixed rates. In terms of oral health, there is poor access and utilization of these schemes.

Conclusion: The ESI scheme and CGHS can be a tool to achieve universal health coverage; however, it needs modification to be utilized to its optimum benefits.

Keywords: Dental care, Dental health, Dental services, Health insurance.

Journal of Oral Health and Community Dentistry (2021): 10.5005/jp-journals-10062-0112
\end{abstract}

\section{INTRODUCTION}

Health care in India is in a state of transition due to the growing economy and increased health consciousness among the people across the sections of the society. The country has achieved a lot in terms of health, like a reduction in maternal and infant mortality rates, an increase in the number of hospitals and health infrastructure. ${ }^{1}$ However, inequalities in access to healthcare remain a challenge.

Orodental diseases are emerging as a major public health problem across the globe. In India, the prevalence of dental caries is reported as low as $22.6 \%$ to as high as $90 \%$ among the different age-group, gender, and geographic area with an increasing trend in the last decade. ${ }^{2-6}$ More than $50 \%$ of the Indian population is suffering from periodontal disease. Untreated chronic periodontitis is responsible for tooth loss in the majority of the cases. The constant presence of chronic inflammation and inflammatory mediators has also been proved to be a significant risk factor of several systemic diseases, e.g., preterm low birth weight babies, coronary artery diseases, diabetes mellitus. These pathologies result in tooth loss, which is reported to be $49.5 \%$ both in children and in adults and increases with age..$^{7-10}$

On the other hand, we have a mixed model of oral health care delivery with the major share from private teaching institutions and private practitioners. In India there area more than 267 dental schools, producing approximately 19,000 dental graduates per year, and 3,000 dental specialists and 1,050 dentists posted in public health centers are available for providing dental care. ${ }^{11}$

Despite this, people are not aware of the importance of oral health and oral hygiene, resulting in low oral health care service utilization. Low utilization has been reported from the previous studies irrespective of age, gender, and geographic location. Among those who utilized the services, only $22 \%$ used it for simple treatments such as extraction or pain-relieving. Forty percent of populations do not use oral health services due to the high cost of dental care, so many of them suffer from pain. ${ }^{12-15}$
${ }^{1,2}$ Department of Public Health Dentistry, MR Ambedkar Dental College and Hospital, Bengaluru, Karnataka, India

Corresponding Author: Umashankar Gangadharaiah Kadaluru, Department of Public Health Dentistry, MR Ambedkar Dental College and Hospital, Bengaluru, Karnataka, India, e-mail: drumashankargk@gmail.com How to cite this article: Kadaluru UG, Naryanappa RJ. Social Insurance for Oral Healthcare: Analysis of Two Insurance Schemes in India. J Oral Health Comm Dent 2021;15(3):122-128.

Source of support: The study is funded by Rajiv Gandhi University of Health Sciences, Bengaluru, Karnataka. Grant No: RGU:Adv. Res:proposal-D-19:2015=-16.

Conflict of interest: None

Health insurance in Western countries has shown a strong association with the use of dental services and increases the demand for service irrespective of age, gender, and socioeconomic status with little benefits or cap in the coverage (79\% utilization rate with insurance). ${ }^{16-18}$ Unlike most Western countries, specific dental insurance plans are uncommon in India. Some health insurances cover dental procedure requiring hospitalization, and some cover minimal procedures such as extraction, root canal treatment, and $\mathrm{X}$-ray. However, private health insurance is not affordable to the majority of the population.

Social insurance is welfare state program in a Bismarckian model of health care to increase access to oral health care for the population. The two most popular social health insurance schemes in India are Central Government Health Scheme (CGHS) and Employees' State Insurance (ESI) Scheme which cater to the people, working in the organized sector. ESI scheme is the first multidimensional social security scheme introduced in 1952 and gives comprehensive medical care for the insured person and their dependents. There is no mention of the dental health benefits anywhere under the scheme but offers a range of dental 
treatments through the dental units of its hospitals and also through its empaneled clinics. ${ }^{19,20}$

Similarly, the CGHS provides comprehensive healthcare facilities for the central government employees, pensioners, and their dependents residing in CGHS-covered cities. The CGHS provides comprehensive health care to 3 million CGHS beneficiaries in India through CGHS centers and panels of hospitals and clinic. ${ }^{21}$

There are no data on the number of beneficiaries utilizing the dental services or type of oral health services utilized, etc. These schemes provide intangible opportunities to study the implications of social security schemes concerning oral health especially in a setting like India. Hence, an attempt has been made to describe the current scenario of the social insurance schemes with regard to oral health care in India and to analyze it critically with regard to its performance in terms of equity and efficiency and utilization.

\section{Methodology}

For the study, a mixed-method approach involving both qualitative analysis through interviews and the quantitative analysis through case studies of the scheme was undertaken.

\section{Qualitative Analysis}

A semi-structured interview was done on informed persons of the schemes using the World Health Organization (WHO) conceptual framework for healthcare financing and template adopted by Shahram Yazdani (2010). ${ }^{22}$ The field notes were taken, and the report was prepared based on the responses with an emphasis on oral health care services.

\section{Quantitative Analysis}

We adopted a case study approach using the information available in the annual report series of the CGHS and ESI scheme. The information was collected through RTI 2003 Act. Further, these reports were assessed for information specific to oral health care under the schemes, and the report was prepared.

\section{Results}

\section{Employees' State Insurance (ESI) Scheme}

This scheme is an integrated measure of social security under the Employees' State Insurance Act of 1948. The scheme provides an array of benefits such as sickness, maternity, disablement, and death due to employment injury and to provide medical care to insured persons and their families.

As per the Act, the ESI scheme applies to factories and other establishments, viz., road transport, hotels, restaurants, cinemas, newspapers, shops, and educational/medical institutions wherein 10 or more persons are employed. The employees of the aforesaid categories of factories and establishments, drawing wages up to Rs. 15,000/- a month, are entitled to social security cover under the ESI Act. Presently, i.e., since 2019, drawing wages inclusion under ESI is raised to Rs. 21,000/-. The finance contributions for the scheme are shared from employers and employees at a rate of 4.75 and $1.75 \%$ of the wages payable to employees. Also, employees earning less than Rs. 137/- a day as daily wages are exempted from payment of their share of contribution.

Characteristics of the beneficiaries, when analyzed for the past 5 years, showed that at present 13 crores and 32 lakhs beneficiaries are registered under the ESI scheme. Of these beneficiaries, $3,11,18,680$ are employees and 3,43,31,300 dependents. The proportion of women insured is less compared to the total population. The total number of beneficiaries is increasing every year at an average rate of $5.25 \%$ annually (Table 1 ).

As per the report, 10,33,730 establishments are registered under the scheme, and the numbers are also showing a steady increase over the years. Since 2014, beneficiaries registered under the scheme are growing at an average rate of $11.34 \%$. Similarly, the numbers of dispensaries have increased over the years from 1,418 in 2013-2014 to 1,489 in 2018. However, hospital annexes remain the same. In pace with the employees and establishments under the scheme, the income to the scheme has also increased from 11,909 crores in the year 2013 to 23480.37 crores in the year 2018 (Tables 2 and 3).

\section{Central Government Health Scheme (CGHS)}

Central Government Health Scheme: This is a scheme for providing comprehensive medical care to the Central Government employees and pensioners enrolled under the scheme. It caters to the health care needs of beneficiaries of Legislature, Judiciary, Executive, and the Press population.

CGHS provides healthcare through different system stems of medicine, i.e., allopathic, homeopathic, and Indian systems of medicine (Ayurveda, Unani, Siddha, and Yoga). Unlike the ESI, the

Table 1: Characteristics of the beneficiaries under ESI scheme (year-wise) (Source: Annual Reports of ESI)

\begin{tabular}{|c|c|c|c|c|c|c|}
\hline \multirow[b]{2}{*}{ Sl. No } & \multirow[b]{2}{*}{ Characteristics of the beneficiaries } & \multicolumn{5}{|c|}{ Report year } \\
\hline & & $2017-2018$ & $2016-2017$ & $2015-2016$ & 2014-2015 & 2013-2014 \\
\hline 1 & No. of employees & $31,118,680$ & $29,321,060$ & $18,921,250$ & $17,954,970$ & $17,412,130$ \\
\hline 2 & No. of insured persons/family units & $34,331,300$ & $31,962,910$ & $21,361,880$ & $20,343,800$ & $19,547,620$ \\
\hline 3 & No. of insured women & $4,542,029$ & $4,089,773$ & $3,786,827$ & $3,360,697$ & $2,922,345$ \\
\hline 4 & Total beneficiaries & $133,205,444$ & $124,016,091$ & $82,884,094$ & $78,933,944$ & $75,844,766$ \\
\hline
\end{tabular}

Table 2: Details of the establishment registered and infrastructure for provision of medical care in ESI (Source: Annual Reports of ESI)

\begin{tabular}{llccccc}
\hline & & \multicolumn{5}{c}{ Report year } \\
\cline { 3 - 6 } Sl. No. & Infrastructure & $2017-2018$ & $2016-2017$ & $2015-2016$ & $2014-2015$ & $2013-2014$ \\
\hline 1 & Establishment & $1,033,730$ & 898,138 & 783,786 & 723,756 & 669,880 \\
& covered & & & & 42 & 42 \\
2 & Annexes & 42 & 42 & 151 & 151 & 151 \\
3 & Hospitals & 154 & 151 & 1,489 & 1,459 & 1,418 \\
4 & Dispensaries & 1,489 & 1,489 & &
\end{tabular}


Table 3: Details of the total income and expenditure under ESI for the past 5 years (Source: Annual Reports of ESI)

\begin{tabular}{lccccc}
\hline & \multicolumn{5}{c}{ Report year } \\
\cline { 2 - 6 } Income details & $2017-2018$ & $2016-2017$ & $2015-2016$ & $2014-2015$ & $2013-2014$ \\
\hline Revenue income $^{*}$ & 23480.37 & 16852.38 & 14372.22 & 13588.58 & 11909.44 \\
Revenue & 8541.63 & 9506.54 & 8207.58 & 7606.33 & 6486.61 \\
expenditure & & & & & \\
\hline${ }^{*}$ Rs in crores & & & &
\end{tabular}

Table 4: Showing the contributions of the employees for eligibility of health insurance under CGHS (Source: Annual Report of National Health and Family Welfare 2017-2018)

\begin{tabular}{lcc}
\hline SI. No. & $\begin{array}{c}\text { Corresponding level in the pay matrix } \\
\text { as per 7th central pay commission } \\
\text { (Govt. of India) }\end{array}$ & $\begin{array}{c}\text { Contribution of } \\
\text { employees }\end{array}$ \\
\cline { 2 - 3 } & Level-wise & Rs./month \\
\hline 1 & $1-5$ & 250 \\
3 & 6 & 450 \\
4 & $7-11$ & 650 \\
\hline
\end{tabular}

Table 5: Details of the ward entitlement for the beneficiaries under the CGHS (Source: Annual Report of National Health and Family Welfare 2017-18)

\begin{tabular}{lll}
\hline SI. No. & $\begin{array}{l}\text { Basic pay drawn as per 7th } \\
\text { CPC }\end{array}$ & $\begin{array}{l}\text { Ward entitlement in private } \\
\text { empaneled hospitals }\end{array}$ \\
\hline 1 & Up to Rs. 47,600/- & $\begin{array}{l}\text { General ward } \\
2\end{array}$ \\
3 & Rs. 47,601/- to Rs. 63,100/- & Semi-private ward \\
\hline
\end{tabular}

CPC, central pay commission

fund contribution in CGHS is based upon the salary, as per the 7th pay scale matrix (Tables 4 and 5).

There are 285 allopathic centers, 85 AYUSH centers, 82 laboratories, and 21 dental units serving 32,11,728 beneficiaries, of which $10,68,905$ beneficiaries are the (Table 6). According to the number of beneficiaries, majority, i.e., 15,82,585, are from Delhi followed by Hyderabad 1,84,726, and Mumbai, 1,69,062. There are 21 dental units owned by CGHS, and a total of 86 empaneled dental centers, of which 6 units have National Accreditation Board for Hospitals (NABH) compliance. The maximum centers are in Delhi (Table 6).

Government Health Expenditure (GHE), including capital expenditure, is Rs. $1,61,863$ crores ( $30.6 \%$ of $1.18 \%$ GDP and Rs. 1,261 per capita). This amounts to about $4.07 \%$ of general government expenditure in 2015-2016. Union Government shares 35.6\%, and State Government shares $64.4 \%$ of the health expenses. The CGHS expenditure alone is about Rs. 2,531 crore out of all Government Financed Health Insurance Schemes, which is Rs. 5,064 crores (Table 7).

\section{The Dental Care Provision}

The dental care delivery is provided through the dental units of the ESI model hospitals along with 13 teaching medical hospitals, 2 dental colleges, and other empaneled centers under ESI scheme and 21 dental units and 86 empaneled dental centers in CGHS.

Though there is no specific dental care package under the scheme, the oral health service provision has no cap or sealing and includes comprehensive oral health care. However, under empanelment, the scheme provides reimbursement for 59 listed procedures coded from 174 to 231 (Appendix 1). The charges vary from state to state and depend upon the NABH compliance of the dental unit center. Further, the procedure that is not in the list is covered with preauthorization. Thus, the dental care provisions under these schemes are exhaustive and comprehensive.

Under the ESI scheme, the total number of dentures delivered is inconsistent, with maximum dentures delivered in 2013-2014 of 607 and a minimum of 63 in 2014-2015. The oral health indicators for the past 5 years show that dental disease incidence is increasing and it is more among the family members compared to the insurers. The dental caries incidence is presently at 5.63 cases per thousand among the insured person compared to the 7.87 cases per 1,000 among the family members. The picture is the same for the periodontal diseases as well as the other oral diseases of the jaw and the salivary glands. Further, the incidence of oral disease is also increasing over the period (Tables 8 to 10).

Further, in Bengaluru, only three dental colleges were empaneled during 2015 onward and the amount reimbursed to these centers per annum shows that only a few beneficiaries utilized the dental services (Table 11).

Similarly, under CGHS, 16,133 beneficiaries have received the dental care in Mumbai, 4,345 in Kolkata, and 6,000 in Bengaluru and Pune for the year 2018. Also when the type of services received enquired only in Mumbai and Bengaluru, they have received all kinds of procedures, whereas in other centers, it is outpatient department (OPD) or simple procedure only (Table 12).

Looking at the vacancy of the dentist, to date the total sanctioned post is only 36 dentists for 21 dental units. This accounts for the dentist's beneficiary ratio of 1:82,006 (Table 13).

These above observations show poor utilization for dental services among the beneficiaries and poor distribution of the dentists in the scheme and fewer priorities to the dental services.

\section{Discussion}

India has a mixed model of healthcare delivery with both private and public providers. In terms of oral health, the majority of dental care delivery is through private practitioners and private dental teaching hospitals. Presently, many social insurance schemes are functioning in India, mainly ESI, CGHS, Ayushman Bharat, ECHS (Ex-servicemen Contributory Health Scheme), Yashaswini, Arogyashree, etc. Some schemes are common throughout the country, and some are statespecific. However, the large and oldest schemes are ESI and CGHS, The concept started with the ESI scheme in 1952 followed by CGHS in 1954, hence considered for the present study. To our knowledge, this is the first study to look into the social health insurance in terms of oral health. The purpose of this research was to analyze and interpret the performance of social insurance in India in terms of oral health care services with the available evidence.

With the estimated 1.3 billion population of India, the ESI covers $9.7 \%$ (130.32 million) and CGHS covers 3\% (3.5 million) of 
Table 6: Details of the implementation center, number of beneficiaries, and total number of dental units under CGHS (Source: Annual Reports of National Health and Family Welfare)

\begin{tabular}{|c|c|c|c|c|c|c|}
\hline \multirow{2}{*}{$\begin{array}{l}\text { SI. } \\
\text { No. }\end{array}$} & \multirow[b]{2}{*}{ City } & \multirow[b]{2}{*}{ Card holders } & \multirow[b]{2}{*}{ Beneficiaries } & \multirow[b]{2}{*}{ Dental units } & \multicolumn{2}{|c|}{ Empaneled dental centers } \\
\hline & & & & & Non-NABH & $\mathrm{NABH}$ \\
\hline 1 & Agartala & 332 & 1,027 & 0 & - & - \\
\hline 2 & Ahmedabad & 15,499 & 45,457 & 1 & 1 & 0 \\
\hline 3 & Prayagraj & 18,362 & 59,627 & 0 & 2 & 0 \\
\hline 4 & Bengaluru & 40,658 & $1,15,531$ & 1 & 4 & 0 \\
\hline 5 & Bhopal & 5,532 & 15,034 & 0 & Nil & - \\
\hline 6 & Bhubaneswar & 6,298 & 19,294 & 0 & 1 & 0 \\
\hline 7 & Chandigarh & 12,491 & 30,674 & 0 & 2 & 0 \\
\hline 8 & Chennai & 41,347 & $1,10,584$ & 1 & 3 & 0 \\
\hline 9 & Dehradun & 10,116 & 24,120 & 0 & Nil & - \\
\hline 10 & Delhi and NCR & $4,83,598$ & $15,82,585$ & 6 & 46 & 5 \\
\hline 11 & Gandhinagar & 2,382 & 8,853 & 0 & Nil & \\
\hline 12 & Guwahati & 13,465 & 46,018 & 0 & Nil & \\
\hline 13 & Hyderabad & 65,778 & $1,84,726$ & 1 & 1 & 0 \\
\hline 14 & Imphal & 35 & 141 & 0 & & - \\
\hline 15 & Indore & 548 & 1,182 & 0 & Nil & - \\
\hline 16 & Jabalpur & 34,877 & 84,274 & 0 & 5 & 1 \\
\hline 17 & Jaipur & 18,387 & 54,274 & 1 & 2 & 0 \\
\hline 18 & Jammu & 979 & 2,344 & 0 & Nil & - \\
\hline 19 & Kanpur & 30,770 & 83,918 & 1 & 1 & 0 \\
\hline 20 & Kohima & 7 & 15 & 0 & - & - \\
\hline 21 & Kolkata & 55,616 & $1,45,915$ & 1 & Nil & - \\
\hline 22 & Lucknow & 21,233 & 68,439 & 1 & 3 & 0 \\
\hline 23 & Meerut & 13,813 & 40,847 & 1 & 3 & 0 \\
\hline 24 & Mumbai & 55,844 & $1,69,062$ & 3 & 3 & 0 \\
\hline 25 & Nagpur & 29,788 & 79,428 & 1 & 4 & 0 \\
\hline 26 & Patna & 12,871 & 42,436 & 1 & 4 & 0 \\
\hline 27 & Puducherry & 473 & 1,484 & 0 & Nil & - \\
\hline 28 & Pune & 48,679 & $1,14,041$ & 1 & 1 & 0 \\
\hline 29 & Ranchi & 4,838 & 15,340 & 0 & Nil & - \\
\hline 30 & Shillong & 4,948 & 17,042 & 0 & Nil & - \\
\hline 31 & Shimla & 772 & 1,990 & 0 & Nil & - \\
\hline 32 & Thiruvananthapuram & 15,129 & 37,672 & 0 & Nil & - \\
\hline \multirow[t]{2}{*}{33} & Visakhapatnam & 3,440 & 8,354 & 0 & Nil & - \\
\hline & Total & $10,68,905$ & $32,11,728$ & 21 & 80 & 6 \\
\hline
\end{tabular}

the population, totally covering approximately $12 \%$ of the country population. ${ }^{23}$ Also, the proportion of women beneficiaries is less compared to the actual population. This is because the population covered under the schemes is people under organized sectors, and there is a less number of women working in the organized sector. This poses an issue of equity of the schemes in terms of gender. ${ }^{24}$ However, ESI has extended its services to informal sectors to provide health services to the poor but has seen little success. In addition, Ayushman Bharat, a major initiative of Central Government of India aiming to achieve universal health coverage, covers 10 crore poor families, across the country to reach ( 0.5 billion) $37 \%$ of the population but the oral health is poorly addressed. ${ }^{25}$

Over the years, the ESI and CGHS show an increase in the number of beneficiaries. This growth in numbers is attributed to higher wage ceilings coming in the purview of ESI and growth in the number of workers employed in the organized sector. This increasing trend clearly suggests that there is a huge number of population under the schemes and need for dental care for this population.

Both the ESI scheme and the CGHS are welfare state programs, and the financial contribution from the beneficiaries is very minimal 
Table 7: Income and expenditure of CGHS (Source: Annual Reports of National Health and Family Welfare)

\begin{tabular}{lccccc}
\hline $\begin{array}{l}\text { Report } \\
\text { year }\end{array}$ & $\begin{array}{c}\text { Non-plan } \\
\text { revenue }\end{array}$ & Plan revenue & $\begin{array}{c}\text { PORB } \\
\text { revenue }\end{array}$ & $\begin{array}{c}\text { Total } \\
\text { revenue }\end{array}$ & $\begin{array}{c}\text { Total } \\
\text { expenditure }\end{array}$ \\
\hline 2015-16 & 815 & 139.00 & 1065.00 & 2019.00 & 1976.59 \\
$2016-17$ & 890 & 115 & 1,240 & 2,245 & 2206.52 \\
\hline & Revenue & Capital head & PORB & Total & \\
\hline $\begin{array}{l}2017-18 \\
\text { (BE) }\end{array}$ & 1202.79 & 43.70 & 1402.79 & 2649.28 & \\
\hline
\end{tabular}

Table 8: Details of the dental treatment delivered (artificial dentures) under ESI scheme (year-wise) (Source: Annual Reports of ESI)

\begin{tabular}{llllll}
\hline & \multicolumn{5}{c}{ Report year } \\
\cline { 2 - 6 } $\begin{array}{l}\text { Dental } \\
\text { treatment }\end{array}$ & $2017-$ & $2016-$ & $2015-$ & $2014-$ & $2013-$ \\
\hline $\begin{array}{l}\text { No. of dentures } \\
\text { delivered }\end{array}$ & 533 & 72 & 88 & 63 & 607 \\
\hline
\end{tabular}

Table 9: Details of the incidences of oral diseases among the insured person under the ESI scheme (Source: Annual Reports of ESI)

\begin{tabular}{|c|c|c|c|c|}
\hline \multirow{2}{*}{$\begin{array}{l}\text { Incidences of } \\
\text { oral diseases }\end{array}$} & \multicolumn{4}{|c|}{ Report year } \\
\hline & 2014-2015 & $2015-2016$ & 2016-2017 & 2017-2018 \\
\hline Dental caries & 3.99 & 5.15 & 5.67 & 5.63 \\
\hline $\begin{array}{l}\text { Other } \\
\text { disorders of } \\
\text { teeth and } \\
\text { supporting } \\
\text { tissues }\end{array}$ & 3.39 & 4.34 & 4.73 & 5.96 \\
\hline $\begin{array}{l}\text { Other } \\
\text { diseases } \\
\text { of the oral } \\
\text { cavity/ } \\
\text { salivary } \\
\text { glands/jaw }\end{array}$ & 0.75 & 1.29 & 1.22 & 1.29 \\
\hline
\end{tabular}

Table 10: Details of the incidences of oral diseases among the dependents of ESI insured under the scheme (Source: Annual Reports of ESI)

\begin{tabular}{lcccc}
\hline & \multicolumn{4}{c}{ Report year } \\
\cline { 2 - 5 } Oral diseases & $2014-2015$ & $2015-2016$ & $2016-2017$ & $2017-2018$ \\
\hline $\begin{array}{l}\text { Dental caries } \\
\text { Other disorders } \\
\text { of teeth and } \\
\text { supporting }\end{array}$ & 4.06 & 5.34 & 5.85 & 7.87 \\
tissues & & & & \\
$\begin{array}{l}\text { Other } \\
\text { diseases of the } \\
\text { oral cavity/ } \\
\text { salivary glands/ } \\
\text { jaw }\end{array}$ & 0.52 & 4.32 & 4.71 & 6.21 \\
*Values are per thousand populations & 1.32 & 1.20 & 1.97 \\
\end{tabular}

Table 12: The dental care-use indicators under CGHS in selected implemented areas (Source: Obtained through RTI 2003)

\begin{tabular}{lcc}
\hline \multirow{2}{*}{$\begin{array}{l}\text { CGHS-implemented } \\
\text { areas }\end{array}$} & \multicolumn{2}{c}{ Dental care indicators } \\
\cline { 2 - 3 } & $\begin{array}{c}\text { No. of beneficiaries } \\
\text { received dental care }\end{array}$ & $\begin{array}{c}\text { Type of services } \\
\text { received }\end{array}$ \\
\hline Kolkata & 4,345 & OPD $^{*}$ \\
Bengaluru & $28^{*}$ & General dentistry \\
Mumbai & 16,133 & All \\
Pune & 6,152 & Simple procedures \\
\hline *OPD, outpatient department &
\end{tabular}

Table 13:The vacancy position sanctioned, filled, and vacant in dental units of CGHS (Source: Annual Reports of National Health and Family Welfare)

\begin{tabular}{lccc}
\hline & \multicolumn{3}{c}{ Vacancy position } \\
\cline { 2 - 4 } Year & Sanctioned & Filled & Vacant \\
\hline 2015 & 37 & 26 & 11 \\
2016 & 37 & 27 & 10 \\
2017 & 37 & 36 & 1 \\
\hline
\end{tabular}

with approximately $5 \%$ and the government contribution is $95 \%$. The government contribution is very generous in comparison with the benefits package offered by these schemes. The contribution in the ESIS is proportionate and progressive. But still, the common notion is that especially regarding ESI, the poor pays for the poor and less equitable. A better contributory mechanism would be if high wage earners are also included in the scheme, the crosssubsidy through pooling can be carried out more effectively to be more equitable for the population. ${ }^{26}$

The CGHS and ESIS are the schemes that provide comprehensive health coverage, including hospitalization. The provision of health services under CGHS is uncapped and provided through public hospitals with some specialized treatment (with reimbursement ceilings) permitted at private hospitals. The CGHS is unique in the sense that it offers a range of health services through both allopathic dispensaries and the units of alternative medicines such as homeopathy and Ayurveda. The ESIS is also unique in the sense that apart from preventive, outpatient, and inpatient medical care, it also provides compensatory cash benefits for loss of wages, disability benefits are distinguished by permanent and temporary disability, and a maternity cash program is among other benefits offered.

Like other social health insurance schemes, the pooling of revenue is fragmented from employees, employer, and the services offered, which vary from scheme to scheme. The major expenditure in the ESI scheme is on medical benefits, followed by the administrative and cash benefits. Strategic planning of expenditure can equitably distribute the benefits under the scheme. In terms of dental care, there is no separate allocation of funds, and also, there are no robust data on oral health expenditure in the schemes. This inefficiency may affect the efficiency of the scheme to its full benefit and particularly

Table 11: Details of reimbursement to the Empanelment Hospitals in Karnataka under ESI (Source: Obtained through RTI 2003)

\begin{tabular}{llcccc}
\hline Place & Empaneled centers & 2013-2014 & 2014-2015 & $2015-2016$ & $2016-2017$ \\
\hline ESI Rajaji Nagar & KLES Institute of Dental Sciences & 18,579 & 119,960 & 133,195 & 24,110 \\
& Rajarajeswari Dental College & - & 234,932 & 415,275 & 387,421 \\
& MR Ambedkar Dental College & - & - & - & 147,120 \\
\hline
\end{tabular}


for dental care. There is a need to address this aspect to achieve universal health coverage through social insurance schemes.

There are no special benefit packages for dental care, it is included as part of the medical care benefits package, the dental care provisions are comprehensive but unfortunately, the preventive services are not included. The ESI and CGHS dental care providers are better in comparison with Ayushman Bharat, which covers only a few OPD dental procedures and those requiring hospitalization. Moreover, the service provider in Ayushman Bharat is through public hospitals and contracted providers. ${ }^{25}$ Also, Ayushman Bharat is at its infancy in India. This emphasizes the importance of the ESI and CGHS for oral health provision in India.

Further, when compared with other developed and developing countries, the social insurance schemes do provide dental care but will have either cap or sealing of services. In Australia, the universal public health insurance program has dental packages under schemes A, B, and C, which includes preventive, diagnostic, restorative, and denture procedures (excluding root canal treatment $(\mathrm{RCT})$ and crown and bridges). The Medicaid and Medicare Part-A of the United States will cover children up to 21 years and population above 65 years with limited dental care service using copayment mechanism. 27,28

Similarly, in China, urban employment-based basic medical insurance (launched in 1998), urban resident basic medical insurance (launched in 2009), and the new cooperative medical scheme for rural residents (launched in 2003) provide limited dental benefits. Dental services are fully covered for children under the age of 18 years. Outpatient prescription drugs, adult dental care, physiotherapy, and optometry services are provided with subsidized cost-sharing for those aged 18 and older in Denmark universal health coverage. Coinsurance rates are applied to all health services, and for dental services, it is $30 \%$ in France. However, countries like Japan and Canada provide most of the dental care under their social health insurance scheme. ${ }^{29,30}$

Though dental visit and frequency of dental visit is the actual measure of utilization, we did not observe the same in the available data. However, in ESI schemes, the incidence of the dental disease has been reported. Accordingly, the maximum incidence rate for dental caries is 5.6 for the insured person and 7.8 for the dependents per thousand populations, which is very low. Similarly, under the CGHS, the data from the selected city also show poor utilization.

Oral health care utilization is a multifactorial phenomenon that depends on sociodemographic characteristics of the individuals, perceived dental health, people's health beliefs and attitudes, financial problems, and organization of oral health care services. ${ }^{31}$ The result of the present study indicates that the social insurance has overcome the cost barrier and provides a range of oral service; still, the dental service utilization is poor.

In contrast, the United States Medicaid programs show that the overall utilization varies from 26 to $51 \%$ with a variation in age, length of the enrollment, and the disability of the children. The study from Canada suggests that dental utilization increases with insurance and socioeconomic gradient. ${ }^{32,33}$

The reason for the lower utilization is due to the fact that either the beneficiaries are not aware of the dental coverage or they do not perceive the need for oral health. The studies have supported that coverage per se had no apparent effect on the demand for dental services and those who are covered and aware of dental services had shown better utilization and demand for dental care. ${ }^{34,35}$ At this point, we would like to recommend that efforts should be directed to make oral health priorities for all the stakeholders of the schemes.
Also, there is very limited monitoring of schemes in the absence of robust and reliable data. There is hardly any process for taking action based on data that have been generated and reported. Hence, there is a disproportionate rise in the covered population and an inadequate level of utilization.

Unlike the social insurance scheme around the world, where the service should be purchased from a general dentist or public hospitals, we would like to highlight the fact that ESI scheme and CGHS are very unique and most of the services are provided by their own hospitals and dental units, thus increasing the equity and access to all the beneficiaries.

However, there are private centers on contract in both the schemes with reimbursement model but the number is proportionately lesser and seems to be inadequate compared to the number of beneficiaries. This is absolutely true in terms of dental care benefits due to the fact that dental care delivery in India is majorly through private practitioners and teaching dental institutes and the number of participants in the empanelment under both the schemes is less. This reflects the situation where providers are on one side and the beneficiaries are on the other. This low participation may be attributed to the fact that contract providers are paid at a fixed CGHS and ESI rate for 59 procedures, which is much lesser than the usual charges of the private practicing dentist. However, the teaching dental institutes provide the full range of dental services at subsidized rates for dental care with access to specialist manpower.

Presently, the data show that in Bengaluru city, only two or dental colleges are empaneled under the scheme against 14 dental colleges under ESI and none under CGHS. There are approximately 5 million beneficiaries under ESI and more than one lakh beneficiaries under the CGHS. The situation is the same across the country. Hence by understanding the importance of including the private dental care delivery in these schemes, we recommend encouraging the strategic involvement of private participants as a measure to increase access to the beneficiaries (report of ESI and (GHS). The same iterated data are submitted by a high-level committee report in Rajya Sabha (the upper house of parliament) regarding the improvement of CGHS regarding dental care, which suggest that the committee takes note of the effort to outsource the dental services through public-private partnership (PPP) mode in 13 selected wellness centers in division A (central and south zones) apart from CGHS-empaneled dental centers/government hospitals and polyclinics where dental treatment services can be availed. The same procedure of outsourcing could be utilized in other centers so that all the beneficiaries across the country can avail of dental care facilities. The quality, efficacy, and adequacy of dental services should be closely monitored. Hence, the increased number of dental empanelment can be expected. ${ }^{36}$

\section{Conclusion and Recommendations}

A robust data are necessary for any analysis, and the data related to oral health under the schemes were limited except to the information which is presented in the study. Our efforts to gather more information had little success as the authorities did not cooperate. Hence, we have limited our observations to the available data case study only and did not attempt any statistical evaluation.

Within the limitation, the present findings indicate that ESI and CGHS across India's social health insurance scheme are accessible to $12 \%$ of the population. The women's beneficiaries are proportionately less. These schemes are unique; in terms of dental benefits, they provide a range of services much better compared to 
other social insurance within the country and outside but their use is poor. In addition, preventive oral health services are not available and there is a disproportionate distribution of dental manpower under both the schemes.

We recommend modifying these insurance schemes to facilitate optimal use of oral health care services; to maintain separate oral health data bank related to oral health under both the schemes; and to establish a committee to review and draw policies based on the exclusive data related to oral health at regular intervals.

To address the cost issues, a separate dental allocation is necessary for better access and availability of services; there is a need for higher participation of private dentists to be under contract in the insurance scheme.

To encourage dentists' participation in an insurance scheme, payments that dentists receive for providing services must be appropriate in relation to their costs for providing those services.

To improve the utilization, there is a need for oral health care policy within the schemes with an emphasis on preventive care, which should include obligatory regular dental check-ups and the maximum coverage and inclusion of all preventive services in the insurance programs.

\section{References}

1. Srinivasan R. Health care in India. Issues and prospects. The report plus background papers; report of the Committee on India. Indian vision 2020. Planning Commission, Govt. of India; 2004. p. 327-360.

2. Moses J. Prevalence of dental caries, socio-economic status, and treatment needs among 5 to 15 -year-old school-going children of Chidambaram. J Clin Diagn Res 2011;5(1):146-151.

3. Srivatsav R, Nongynirh B, Mathur VP, et al. High burden of dental caries burden in the geriatric population of India: a systematic review. Indian J Public Health 2012;56(2):129-132. DOI: 10.4103/0019-557X.99903.

4. Saravanan S, Anuradha KP, Bhaskar DJ. Prevalence of dental caries and treatment needs among school-going children of Pondicherry, India. Indian Soc Pedod Prev Dent 2003;21(1):1-12. PMID: 12885002.

5. Grewal H, Verma M, Kumar A. Prevalence of dental caries and treatment needs amongst the school children of three educational zones of urban Delhi, India. IJDR 2012;22(4): 517-519. DOI: 10.4103/0970-9290.90283.

6. Grewal H, Verma M, Kumar A. Prevalence of dental caries and treatment needs in the rural child population of Nainital district, Uttaranchal. Indian Soc Pedod Prev Dent 2009;27(4):224-226. DOI: 10.4103/0970-4388.57657.

7. Shaju J. Prevalence of periodontitis in the Indian population: a literature review. J Indian Soc Periodontol 2011;15(1):29-34. DOI: 10.4103/0972-124X.82261.

8. Marya CM, Kumar V, Khatri M, et al. Prevalence of periodontal diseases in India. J Oral Health Comm Dent 2010;4(Spl):7-16. DOI: 10.5005/johcd4-Spl-7.

9. George B, John J, Saravanan S, et al. Prevalence of permanent tooth loss children and adults in the suburban area of Chennai. IJDR 2011;22(2):364. DOI: 10.4103/0970-9290.84284.

10. Patil VV, Shigli K, Hebbal M, et al. Tooth loss, prosthetic status and treatment needs among industrial workers in Belgaum, Karnataka. India J Oral Sci 2012;54(4):285-292. DOI: 10.2334/ josnusd.54.285.

11. Ahuja NK, Parmar R. Demographics \& current scenario with respect to dentists, dental institutions \& dental practices in India. Indian J Dent Sci 2011;3(2):8-11. E ISSN 2231-2293; p ISSN 0976-4003.

12. Kakatkar G, Bhat N, Agarwal A. Barriers to the utilization of dental services in Udaipur, India. J Dent 2011;8(2):81-89. PMID: 21998813; PMCID: PMC3184738.
13. Fotedar S, Sogi SGM. Barriers to utilization of dental services in Shimla India. Eur J Gen Dent 2013:2(2);139-143. DOI: 10.4103/22789626.112314.

14. Kadaluru UG, Kempraj VM, Muddaiah P. Utilization of oral health care services among adults attending community outreach programs. Indian J Dent Res 2012;23(6):841-842. DOI: 10.4103/0970-9290.111290.

15. Poudyal S. Utilization of dental services in a field practice area in Mangalore, Karnataka. Indian J Community Med 2010;35(3):424-425. DOI: 10.4103/0970-0218.69278.

16. Grembowski D, Conrad D, Milgrom P. Utilization of dental services in the United States - an insured population. Am J Public Health 1985;75(1):87-89. DOI: 10.2105/ajph.75.1.87.

17. Pizarro V. The utilization of dental care services according to health insurance coverage in Catalonia Spain. Community Dent Oral Epidemiol 2009;37(1):78-84. DOI: 10.1111/j.1600-0528.2008.00439.x.

18. A growing problem: oral health coverage, access, and usage in Colorado. CHAS issue brief. Colorado Trust; 2011. Available from: www.coloradotrust.org.

19. Aarogyam - a handbook of ESIC hospitals. Available from: www.esic. nic.in/publishing.

20. ESIC notification for empanelling of notifications and No. 532/ U/16/25/2011-12/Emp.Date:04-02-2012. Available from: www.cghs. msotransperent.nic.in.

21. Cashion SW. Children's utilization of dental care in the NC Medicaid program. Pediatr Dent 1999;21(2):97-103. PMID: 10197333.

22. Jadidfard MP, Yazdani S, Khoshnevisan MH. Social insurance for dental care in Iran: a developing scheme for a developing country. Oral Health Dent Manag 2012;11(4):189-198. PMID: 23208596.

23. GOI. Census of India 2001: provisional population totals. New Delhi, India: Registrar General and Census Commissioner of India, Ministry of Home Affairs; 2001.

24. World Bank Group. Labor force participation rate, male (\% of male population ages 15+) (Modeled ILO Estimate), India. 2019.

25. GOI. Arogya Manthana an annual report 2018-19 of Ayushman Bharat PM JAY, National Authority of Health Publication, India. 2019.

26. Reddy KS, Selvaraj S, Rao KD, et al. A critical assessment of the existing health insurance models in India. Report submitted by Public Health Foundation of India; 2011

27. Armstrong $\mathrm{K}$, Campbell M. Costing a social insurance scheme for dental care [Supplementary Report]. NHHRC; 2008.

28. Medicare and you National Medicare Handbook 2017, Centers for Medicare \& Medicaid Services, U.S. Department of Health And Human Services.

29. Mossialos E, Djordjevic A, Osborn R, et al. International profiles of the health care system. The Commonwealth Fund Publication; 2017.

30. McClymont E. Dental care in Canada: the need for incorporation into publicly funded health care. UBCMJ 2015:7.1(28-29).

31. Ekanayake L, Mendis R. Self reported use of dental services among employed adults in Sri Lanka. Int Dent J 2002;52(3):151-155. DOI: 10.1111/j.1875-595x.2002.tb00620.x.

32. Sánchez-García S, de la Fuente-Hernández J, Juárez-Cedillo T. Oral health service utilization by elderly beneficiaries of the Mexican Institute of Social Security in México City. BMC Health Serv Res 2007;7:211. DOI: 10.1186/1472-6963-7-211.

33. Bhatti T, Rana Z, Grootendorst P. Dental insurance, income and the use of dental care in Canada. J Can Dent Assoc 2007;73(1):57.

34. So FH, Schwarz E. Demand for and utilization of dental services among Hong Kong employees with and without dental benefit coverage. Community Dent Oral Epidemiol 1996;24(3):201-206. DOI: 10.1111/j.1600-0528.1996.tb00842.x.

35. Bayat $\mathrm{F}$, Vehkalahti MM, Zafarmand $\mathrm{AH}$, et al. Dental attendance by insurance status among adults in Tehran, Iran. Int Dent J 2006;56(6):338-344. DOI: 10.1111/j.1875-595x.2006.tb00338.x.

36. GOI. The functioning of Central Government Health Scheme (CGHS), Department-Related Parliamentary Standing Committee Rajya sabha. Report No 71. 2013. 